\title{
ACQUIRED DOUBLE PYLORUS
}

Singapore Med J 2018; 59(6): 335-336 https://doi.org/10.11622/smedj.2018073

Dear Sir,

A double channel pylorus can occur after a fistula develops between the stomach and duodenum. This is an extremely rare endoscopic finding that is often discovered incidentally. We herein report a case of acquired double pylorus likely due to peptic ulcer disease.

A 73-year-old Chinese man with no previous abdominal surgery presented with longstanding upper abdominal pain, which was not associated with melaena or anaemia. The initial impression was gastritis. Gastroscopy that was performed showed a tissue bridge in between two pyloric channels that were communicating with the duodenal bulb (Fig. 1a). The adult-sized gastroscope was able to easily pass through each pyloric lumen (Figs. 1b \& c). The lumen located posteriorly (Fig. 1c) was deformed and smaller, suggesting that it could be the false lumen. In addition, there was pangastritis in the stomach and multiple Forrest III ulcers in D1 (Fig. 1d). Gastric biopsies showed chronic gastritis without evidence of Helicobacter pylori (H. pylori).

Double pylorus is an extremely rare finding with a reported endoscopic incidence of between $0.02 \%$ and $0.08 \%{ }^{(1,2)}$ It may be congenital (due to gastrointestinal duplication) or acquired. If acquired, it is usually a complication of peptic ulcer disease and is hypothesised to be secondary to chronic ulceration at the gastric antrum or duodenal bulb, resulting in a fistulous tract that epithelises. ${ }^{(3)}$ Patients do not have symptoms from the dual pyloric channels and typically present with complications of peptic ulcer disease, such as epigastric pain or gastrointestinal bleeding. ${ }^{(4)}$

Recognition of double pylorus is important for the endoscopist due to the possibility of recurrent ulceration that may occur if the underlying aetiology of peptic ulcer disease is not addressed. Treatment is medical therapy with proton pump inhibitors and triple therapy for $\mathrm{H}$. pylori infection, if it is present. ${ }^{(5)}$ Causative factors for upper gastrointestinal ulceration such as nonsteroidal anti-inflammatory drugs or smoking should be stopped. Patients with dual channel pylorus do not require surgical therapy unless their symptoms are refractory.

Yours sincerely,

Enming Yong ${ }^{1}$, Enhui Yong ${ }^{2}$, Junice Shi Hui Wong ${ }^{1}$, Thomas Wai Thong $\underline{\mathrm{Ho}}^{1}$

${ }^{1}$ Department of General Surgery, Tan Tock Seng Hospital, Singapore, ${ }^{2}$ Acute Medicine Unit, St George’s Hospital, London, United Kingdom. enming.yong@mohh.com.sg
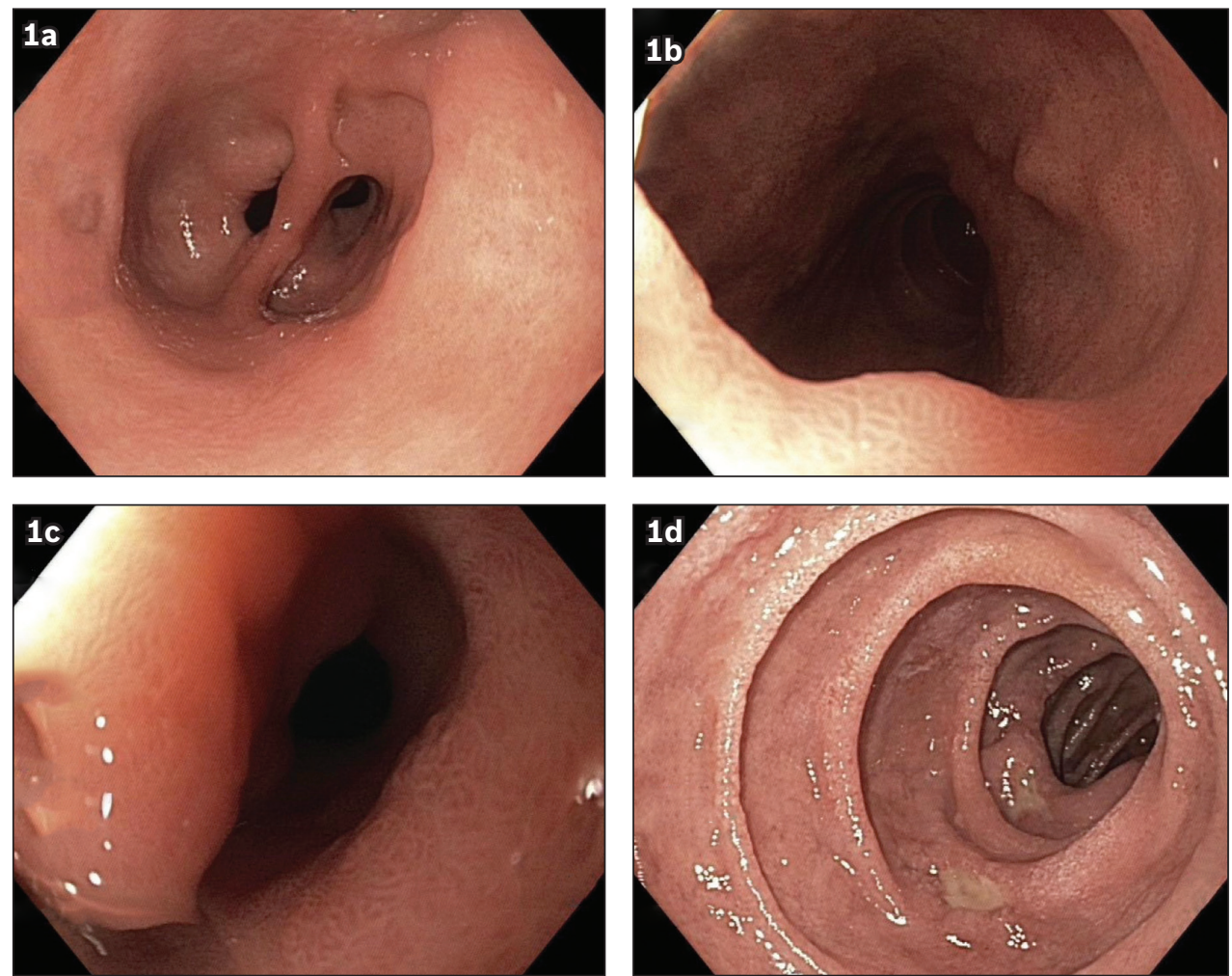

Fig. 1 Gastroscopic images show (a) a tissue bridge in between two pyloric channels that were communicating with the duodenal bulb; (b \& c) the adult-sized gastroscope easily passing through each pyloric lumen; and (d) pangastritis in the stomach and multiple Forrest III ulcers in D1. The lumen located posteriorly (in 1c) was deformed and smaller, suggesting that it was the false lumen. 


\section{REFERENCES}

1. Kothandaraman KR, Kutty KP, Hawken KA, Barrowman JA. Double pylorus--in evolution. J Clin Gastroenterol 1983; 5:335-8.

2. Hu TH, Tsai TL, Hsu CC, et al. Clinical characteristics of double pylorus. Gastrointest Endosc 2001; 54:464-70.

3. Safatle-Ribeiro AV, Ribeiro Júnior U, Habr-Gama A, Gama-Rodriques JJ. Double pylorus: case report and review of the literature. Rev Hosp Clin Fac Med Sao Paulo 1999; 54:131-4

4. Arhan M, Oztas E, Ibis M, Sezgin S, Ozin Y. A rare endoscopic finding: acquired double pylorus. Surg Endosc 2010; 24:244-5.

5. Lei JJ, Zhou L, Liu Q, Xu CF. Acquired double pylorus: clinical and endoscopic characteristics and four-year follow-up observations. World J Gastroenterol 2016; 22:2153-8. 